Article

\title{
Estimating Mangrove Above-Ground Biomass Using Extreme Gradient Boosting Decision Trees Algorithm with Fused Sentinel-2 and ALOS-2 PALSAR-2 Data in Can Gio Biosphere Reserve, Vietnam
}

\author{
Tien Dat Pham $\left.{ }^{1}{ }^{(}\right)$, Nga Nhu Le ${ }^{2, *}$, Nam Thang Ha ${ }^{3,4}{ }^{\oplus}$, Luong Viet Nguyen ${ }^{5}{ }^{(}$, Junshi Xia ${ }^{1}$, \\ Naoto Yokoya ${ }^{1}{ }^{1}$, Tu Trong To ${ }^{5}$, Hong Xuan Trinh ${ }^{5}$, Lap Quoc Kieu ${ }^{6}$ and Wataru Takeuchi ${ }^{7}$ (D) \\ 1 Geoinformatics Unit, RIKEN Center for Advanced Intelligence Project (AIP), Mitsui Building, 15th floor, \\ 1-4-1 Nihonbashi, Chuo-ku, Tokyo 103-0027, Japan; tiendat.pham@riken.jp (T.D.P.); junshi.xia@riken.jp (J.X.); \\ naoto.yokoya@riken.jp (N.Y.) \\ 2 Department of Marine Mechanics and Environment, Institute of Mechanics, Vietnam Academy of Science \\ and Technology (VAST), 264 Doi Can street, Ba Dinh district, Hanoi 100000, Vietnam \\ 3 Faculty of Fisheries, University of Agriculture and Forestry, Hue University, Hue 530000, Vietnam; \\ hanamthang@huaf.edu.vn \\ 4 Environmental Research Institute, School of Science, University of Waikato, Hamilton 3260, New Zealand \\ 5 Remote Sensing Application Department, Space Technology Institute, Vietnam Academy of Science and \\ Technology (VAST), 18 Hoang Quoc Viet street, Cau Giay district, Hanoi 100000, Vietnam; \\ nvluong@sti.vast.vn (L.V.N.); tttu@sti.vast.vn (T.T.T.); hxtrinh@sti.vast.vn (H.X.T.) \\ 6 Thai Nguyen University of Sciences, Tan Thinh Ward, Thai Nguyen City Thai Nguyen University of \\ Sciences, Tan Thinh Ward, Thai Nguyen City 250000, Vietnam; lapkq@tnus.edu.vn \\ 7 Institute of Industrial Science, the University of Tokyo, 4-6-1 Komaba, Meguro-ku, Tokyo 153-8505, Japan; \\ wataru@iis.u-tokyo.ac.jp \\ * Correspondence: lnnga@imech.vast.vn
}

Received: 22 January 2020; Accepted: 25 February 2020; Published: 29 February 2020

\begin{abstract}
This study investigates the effectiveness of gradient boosting decision trees techniques in estimating mangrove above-ground biomass (AGB) at the Can Gio biosphere reserve (Vietnam). For this purpose, we employed a novel gradient-boosting regression technique called the extreme gradient boosting regression (XGBR) algorithm implemented and verified a mangrove AGB model using data from a field survey of 121 sampling plots conducted during the dry season. The dataset fuses the data of the Sentinel-2 multispectral instrument (MSI) and the dual polarimetric (HH, HV) data of ALOS-2 PALSAR-2. The performance standards of the proposed model (root-mean-square error (RMSE) and coefficient of determination $\left(R^{2}\right)$ ) were compared with those of other machine learning techniques, namely gradient boosting regression (GBR), support vector regression (SVR), Gaussian process regression (GPR), and random forests regression (RFR). The XGBR model obtained a promising result with $R^{2}=0.805$, RMSE $=28.13 \mathrm{Mg} \mathrm{ha}^{-1}$, and the model yielded the highest predictive performance among the five machine learning models. In the XGBR model, the estimated mangrove AGB ranged from 11 to $293 \mathrm{Mg} \mathrm{ha}^{-1}$ (average $=106.93 \mathrm{Mg} \mathrm{ha}^{-1}$ ). This work demonstrates that XGBR with the combined Sentinel-2 and ALOS-2 PALSAR-2 data can accurately estimate the mangrove AGB in the Can Gio biosphere reserve. The general applicability of the XGBR model combined with multiple sourced optical and SAR data should be further tested and compared in a large-scale study of forest AGBs in different geographical and climatic ecosystems.
\end{abstract}

Keywords: Sentinel-2; ALOS-2 PALSAR-2; mangrove; above-ground biomass; extreme gradient boosting; Can Gio biosphere reserve; Vietnam 


\section{Introduction}

Mangrove forests are among the most important components of natural ecosystems. They perform a wide range of crucial functions, such as mitigating the effects of tropical typhoons and tsunami, reducing coastal erosion, and storing huge amounts of blue carbon [1,2]. Despite their functions and benefits, mangrove forests have been reduced and degraded worldwide, more seriously in South East Asia, where the decimation rate reached its highest level in the last 50 years [3,4]. The driving factors of mangrove deforestation and degradation are conversion to shrimp aquaculture, agriculture (particularly rice and oil palm in West Africa and Southeast Asia), urban development, poor governance, and overexploitation [3,5]. Unfortunately, the loss of mangrove carbon on large spatial scales is little understood. Without this knowledge, we cannot mitigate the global loss of mangrove habitats [6].

Land-cover change is thought to alter the above-ground biomass (AGB) in the tropical areas [7-9]. By mapping the spatial distribution of mangrove AGB and the carbon stocks associated with external factors, we could detect the changes in mangrove ecosystems, better understand the drivers of these changes, and reduce the uncertainty in estimating the loss of mangrove ecosystem services. A precise estimation of mangrove AGB is required for sustainably preserving and protecting mangrove ecosystems from loss and degradation under climate change and accelerated global warming. However, the complex structure of mangrove ecosystems hindered quantitative estimates of mangrove AGB. Especially, the biosphere reserves of mangroves are characterized by multiple species, very high diversity, and large spatial distributions. During the last 30 years, AGB retrieval of mangroves has been investigated worldwide [10-14]. Mangrove AGB can be accurately estimated from field-based measurements or forest inventory data. However, these approaches are disadvantaged by high cost and site-selection biases [15]. Cost-effective and accurate retrieval techniques for mangrove AGB in tropical and semi-tropical areas would provide baseline data for the monitoring, reporting, and verification schemes adopted in climate-change mitigation strategies, such as Blue Carbon projects and the United Nations' Reducing Emissions from Deforestation and Forest Degradation (REDD+) program in the tropics [16].

In recent years, mangrove AGBs have been increasingly mapped using earth observation (EO) data collected by optical sensors [17-19], synthetic aperture radar (SAR) data [13,20,21], airborne LiDAR [22,23], and LiDAR data acquired form unmanned aerial vehicles (UAV) [24,25]. A few attempts combined the data of multispectral and SAR sensors for mangrove AGB retrieval in tropical regions. Fused data are particularly useful in biosphere reserves comprising multiple mangrove species and rich biodiversity. In such systems, the spatial distribution of the mangrove AGB is difficult to estimate with sufficient accuracy. By accurately estimating the mangrove AGB in biosphere reserves, we could effectively monitor their mangrove ecosystems and implement sustainable mangrove conservation and management.

Models for estimating AGB range from simple to multi-linear regression approaches $[13,21,24]$ to sophisticated machine learning (ML) methods $[17,18,26]$. For mapping and estimating forest AGBs, non-parametric approaches using various ML algorithms have proven more effective than parametric methods using linear models. Meanwhile, numerous EO datasets have been compiled from optical, SAR, and LiDAR data. These data are commonly retrieved from non-parametric regression techniques such as the random forest regression (RFR) algorithm $[17,25,27]$, artificial neuron networks (ANN) [26], and support vector regression (SVR) [28,29]. Recently, gradient boosting decision trees (GBDT) effectively solved regression problems such as evaporation prediction [30] and oil price estimation [31]. The extreme gradient boosting regression (XGBR) algorithm is a particularly potent tool in environmental problems in environmental problems such as urban heat islands [32], algal blooming [33], and energy-supply security issues [34]. However, to our knowledge, the usefulness of the XGBR algorithm in forest AGB estimation, particularly in tropical mangrove habitats, has not been quantified. Especially, the current literature seems to lack a quantitative comparison of state-of-the-art ML techniques for estimating AGBs in different forest ecosystems. 
To overcome these challenges, we estimated the mangrove AGB in the Can Gio biosphere reserve (South Vietnam) using an ML model and the fused data of the Sentinel-2 (S2) MSI and ALOS-2 PALSAR-2 sensors. We selected Sentinel-2 MSI because the multispectral bands of S-2 reflect the forest stand structures such as stem volume, whereas the longer wavelengths of the dual polarimetric $(\mathrm{HH}, \mathrm{HV})$ mode of the ALOS-2 PALSAR-2 sensor can penetrate mangrove forest canopies. The fused S2 MSI and ALOS-2 PALSAR-2 data were processed by a nonlinear regression model in the XGBR algorithm, providing the first estimation of mangrove AGB in the Can Gio biosphere reserve (CGBRS). Additionally, the performance of the XGBR model was compared with those of other GBDT techniques and several well-known ML algorithms (SVR, GPR, and RFR) on mangrove AGB estimation in the same study area. Incorporating the S-2 MSI and ALOS-2 PALSAR-2 data into the proposed model was found to improve the mangrove AGB estimation in a Vietnamese biosphere reserve and is potentially applicable to mangrove conservation in other biosphere reserves.

\section{Materials and Methods}

\subsection{Study Area}

The present study was conducted in Can Gio, a coastal district located approximately $50 \mathrm{~km}$ south of Ho Chi Minh City (formerly Sai Gon) along the Southern coast of Vietnam. The geographical coordinates are $10^{\circ} 22^{\prime}-10^{\circ} 40^{\prime}$ latitude and $106^{\circ} 46^{\prime}-107^{\circ} 01^{\prime}$ longitude. The climate is tropical monsoon and has two typical seasons. The dry season begins in April and ends in November of the following year, whereas the rainy season occurs between May and October. The average temperature is approximately $26^{\circ} \mathrm{C}$, the annual rainfall is roughly $1300-1400 \mathrm{~mm}$, and the relative humidity is approximately $80 \%$ [35]. This district is well-known for its mangrove reforestation and rehabilitation programs, not only in Vietnam but also throughout Southeast Asia [36]. The wetland ecosystem of Can Gio is diverse and includes the mangrove areas distributed in zone IV, which contains the largest mangrove forest among the four mangroves zones (See Figure 1) in Vietnam [37].
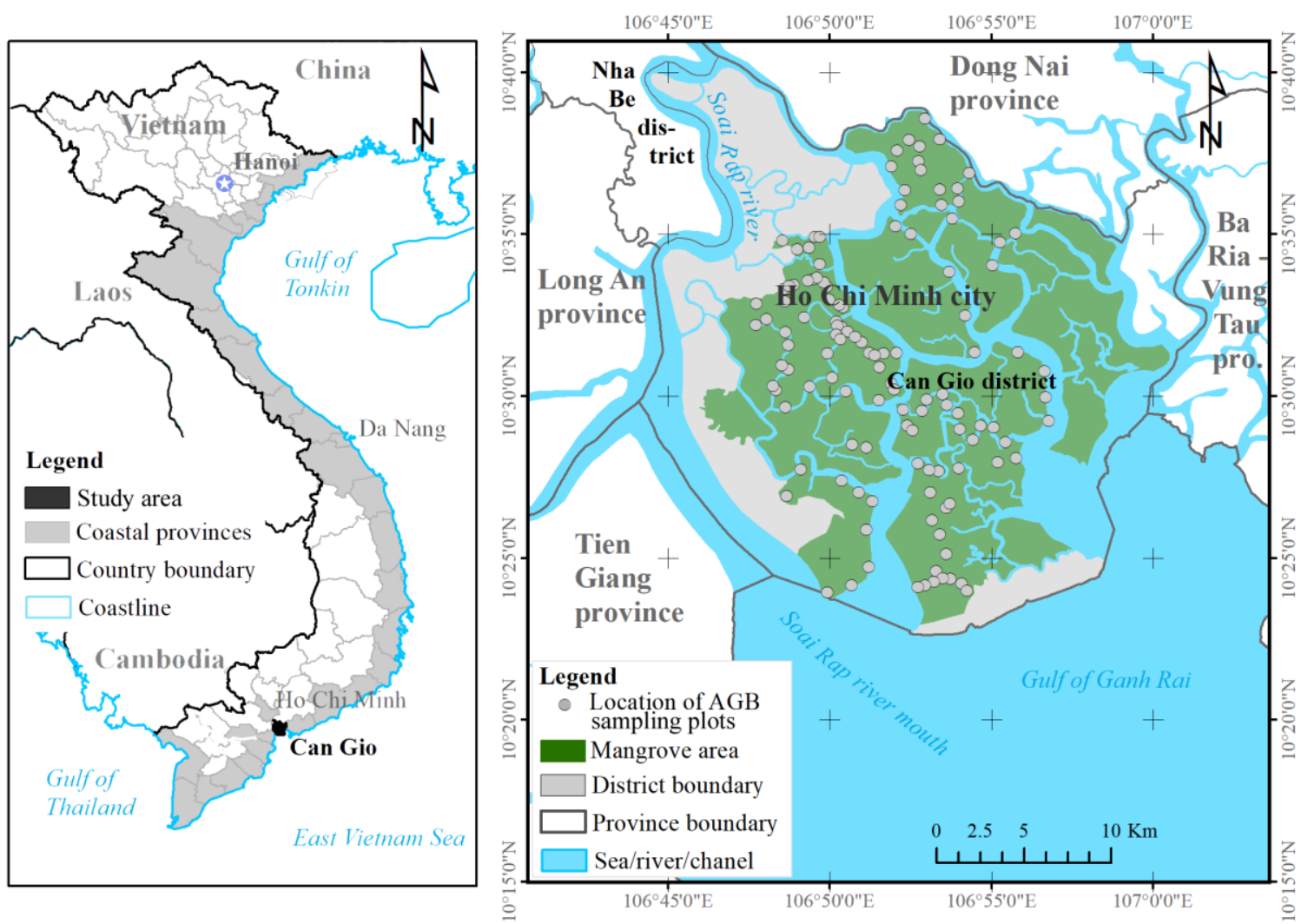

Figure 1. Location map of study areas. 
The Can Gio mangrove forests were declared as a biosphere reserve by the United Nations Educational, Scientific, and Cultural Organization (UNESCO) in 2000 [38]. The dominant species are Rhizophora apiculate, Sonneratia alba, Avicennia alba, Rhizophora mucronata, and others. Approximately 33 species belonging to 15 families have been identified in the CGBRS [36].

\subsection{Field Survey Data Collection}

With permission from the local authorities, the 2018 field survey of the CGBSR was conducted during the dry season, when the coastal tides impacting the mangrove forest were lowest. A total of 121 plots were sampled by the stratified random sampling approach. Each plot sampling was initially assisted by a local counterpart to guarantee the whole range of AGB values over the reserve. During the surveying, the experimenters measured the diameter at breast height $(\mathrm{DBH})$, tree height $(\mathrm{H})$, and tree density. All living mangrove forest stands with $\mathrm{DBH}>5 \mathrm{~cm}$ in a strata plot size of $25 \times 20 \mathrm{~m}$ ( $0.05 \mathrm{ha}$ ) were measured. The location (accuracy $\pm 2 \mathrm{~m}$ ) of each sampling plot was measured by the Garmin eTrex global positioning system (GPS) (Figure 2).

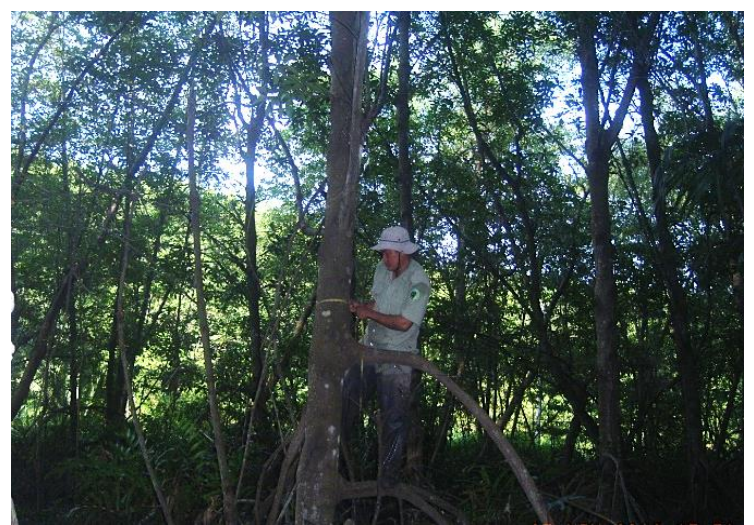

(a)

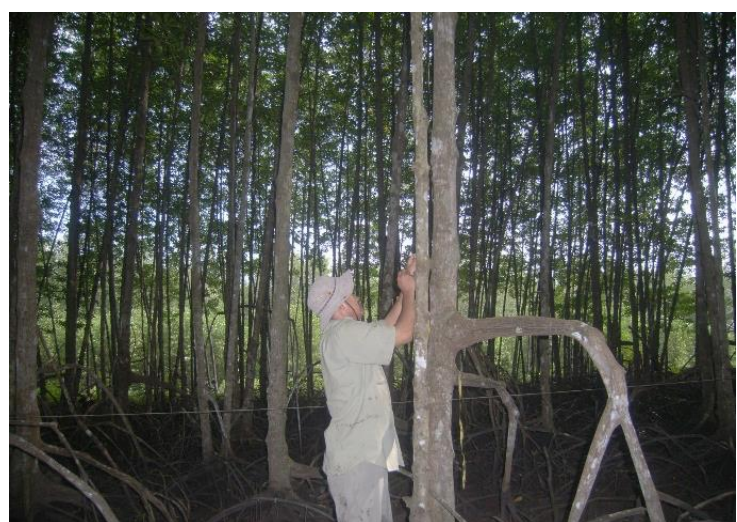

(b)

Figure 2. Aboveground biomass measurements in the study area. (a \& b) Biophysical parameters measurement (Photographs were taken by L.V. Nguyen during the 2018 dry season).

The mangrove AGB of each species was estimated by a specific allometric equation (see Table 1).

Table 1. Allometric equations for estimating the mangrove species in the study site.

\begin{tabular}{ccc}
\hline Species & Allometric Equation & Reference \\
\hline Rhizophora apiculata & $\mathrm{AGB}=0.235 \times \mathrm{DBH}^{2.42}\left(R^{2}=0.98\right)$ & {$[39]$} \\
\hline Avicennia alba & $\mathrm{AGB}=0.140 \times \mathrm{DBH}^{2.40}\left(R^{2}=0.97\right)$ & {$[40]$} \\
\hline Bruguiera gymnorrhiza & $\mathrm{AGB}=0.186 \times \mathrm{DBH}^{2.31}\left(R^{2}=0.99\right)$ & {$[41]$} \\
\hline Bruguiera parviflora & $\mathrm{AGB}=0.168 \times \mathrm{DBH}^{2.42}\left(R^{2}=0.99\right)$ & {$[41]$} \\
\hline Sonneratia caseolaris & $\mathrm{AGB}=0.199 \times \varphi \times 0.90 * \mathrm{DBH}^{2.22}\left(R^{2}=0.99\right)$ & {$[40]$} \\
\hline Lumnitzera racemosa & $\mathrm{AGB}=0.740 \times \mathrm{DBH}^{2.32}\left(R^{2}=0.99\right)$ & {$[42]$} \\
\hline Ceriops zippeliana & $\mathrm{AGB}=0.208 \times \mathrm{DBH}^{2.36}\left(R^{2}=0.96\right)$ & {$[43]$} \\
\hline Xylocarpus granatum & $\mathrm{AGB}=0.082 \times \mathrm{DBH}^{2.59}\left(R^{2}=0.99\right)$ & {$[41]$}
\end{tabular}

Note: AGB is the above-ground biomass $(\mathrm{kg})$ of a mangrove tree, DBH is the diameter $(\mathrm{cm})$ at breast height $(1.3 \mathrm{~m})$, $\varphi$ is the wood density (tons dry matter per $\mathrm{m}^{3}$ fresh volume). 


\subsection{Remote Sensing Data Acquisition and Image Processing}

\subsubsection{Data Acquisition}

The mangrove AGB in the CGBRS was estimated by fusing the ALOS-2 PALSAR-2 L-band dual polarimetric data level 2.1 obtained in high-sensitivity mode with Sentinel-2 (S-2) MSI images. Table 2 presents the S-2 and the ALOS-2 PALSAR-2 data at the study site, acquired on 23 and 24 March during the 2018 dry seasons, respectively.

Table 2. Acquired earth observation data for this study.

\begin{tabular}{|c|c|c|c|c|}
\hline $\begin{array}{c}\text { Earth Observation } \\
\text { Sensor }\end{array}$ & Scene ID & Acquisition Data & Processing Level & $\begin{array}{c}\text { Spectral } \\
\text { Band/Polarizations }\end{array}$ \\
\hline \multirow{2}{*}{ ALOS-2 PALSAR-2 } & ALOS2206940200 & \multirow{2}{*}{23 March 2018} & \multirow{2}{*}{2.1} & \multirow{2}{*}{ L band (HH, HV) } \\
\hline & ALOS2206940190 & & & \\
\hline \multirow{2}{*}{ Sentinel-2 MSI } & S2A_MSI_T48PXS & \multirow{2}{*}{24 March 2018} & \multirow{2}{*}{$1 \mathrm{C}$} & \multirow{2}{*}{11 Multispectral bands } \\
\hline & S2A_MSI_T48PYS & & & \\
\hline
\end{tabular}

To pre-process the satellite remotely sensed data, we resampled both multispectral bands of Sentinel-2 and the dual polarization model of ALOS-2 PALSAR-2 data at ground sampling distance (GSD) of $10 \mathrm{~m}$. The satellite images were processed as described in Section 2.3.2. To validate the model's performance and optimize the hyperparameters for AGB retrieval in the CGBRS, the model was combined with the measured field data. Figure 3 is a flowchart of the satellite-image processing and the generation of mangrove AGB estimation models using the ML techniques in the current study.

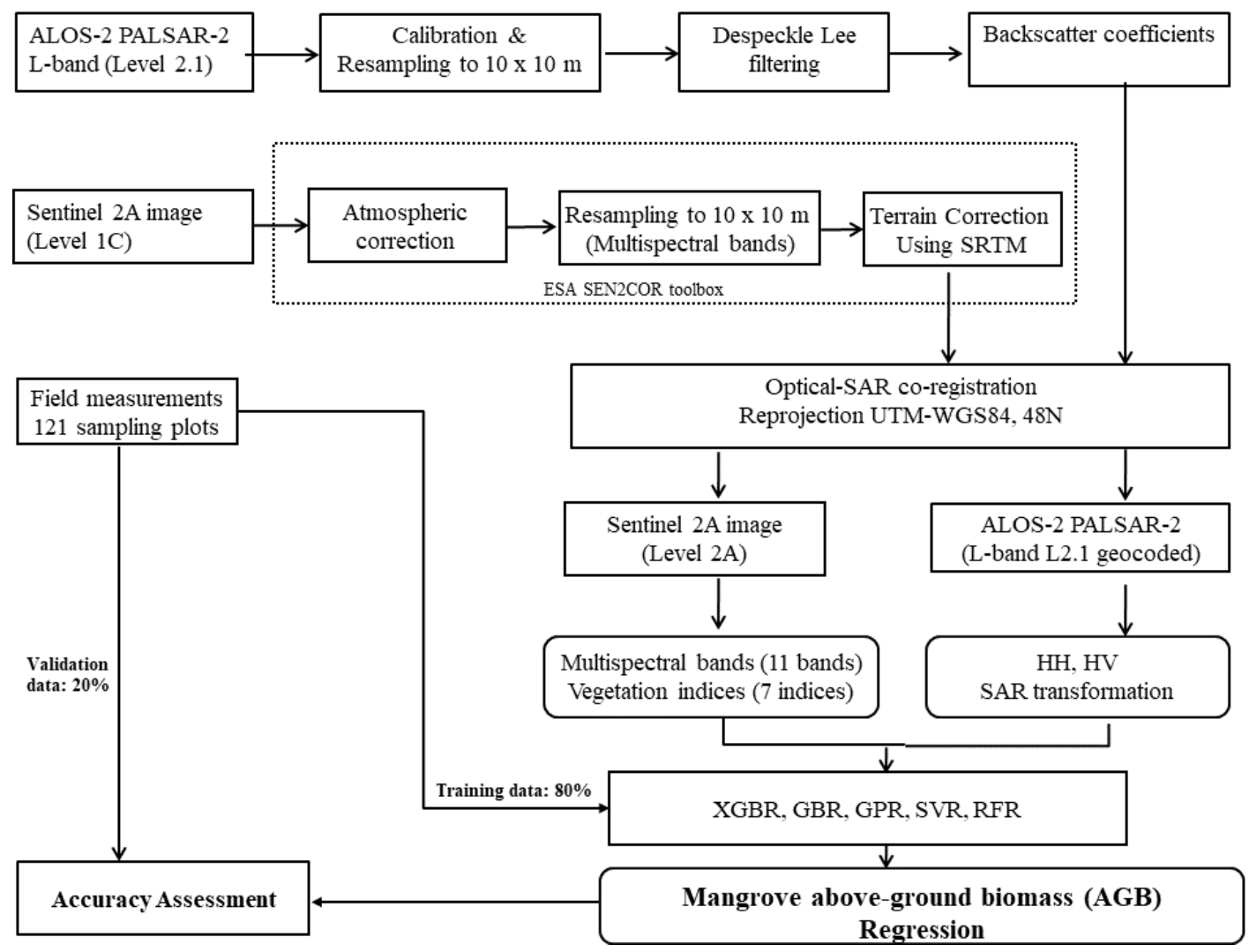

Figure 3. Flowchart for satellite-image processing and the generation of AGB models based on ML techniques. 


\subsubsection{Satellite Image Processing}

Two scenes of the ALOS-2 PALSAR-2 Level 2.1 data acquired on 23 March 2018 during the dry season were download from https://auig2.jaxa.jp/ips/home, the website of the Aerospace Exploration Agency (JAXA). The DN (Digital Number) of the ALOS-2 PALSAR-2 imagery was converted to normalized radar sigma-zero using Equation (1):

$$
\sigma^{0}[\mathrm{~dB}]=10 \cdot \log 10(\mathrm{DN})^{2}+\mathrm{CF}
$$

where $\sigma^{0}$ is backscatter coefficients, and CF is the calibration factor. For $\mathrm{HH}$ and $\mathrm{HV}$ polarizations, $\mathrm{CF}=-83 \mathrm{~dB}$ [44]. Equation (1) converts the $\mathrm{DN}$ of each pixel to sigma naught $\left(\sigma^{0}\right)$ in decibel $(\mathrm{dB})$.

Two scenes of the Sentinel-2 (S-2) Level-1C sensors acquired on 24 March 2018 during the dry season were retrieved from Copernicus Open Access Hub of the European Space Agency (ESA). The radiometric and geometric corrections of the S-2 data were made to the UTM/WGS84, Zone 48 North projection at top-of-atmosphere (TOA) reflectance [45]. The S-2 MSI Level-1C data were processed to Level-2A at the bottom-of-atmospheric (BOA) reflectance using the Sen2Cor algorithm of ESA (http://step.esa.int/main/third-party-plugins-2/sen2cor/). The S-2 and ALOS-2 PALSAR-2 images were processed by the SNAP toolbox, and the modeling process was performed in Python 3.7 environment using the Scikit-learn library [46].

\subsubsection{Transformation of Multispectral and SAR Data}

As a commonly employed method in previous mangrove AGB retrievals $[13,47,48]$, image transformation was applied to the multispectral and SAR data of the present study. The image transformation of SAR data involves a combination of multi-polarizations such as $\mathrm{HV} / \mathrm{HH}, \mathrm{HH} / \mathrm{HV}$, and $\mathrm{HH}-\mathrm{HV}$, as suggested in [26]. Meanwhile, multispectral data are transformed using the vegetation indices, as each index is sensitive to mangrove structure and biomass. Table 3 shows the seven vegetation indices chosen for mangrove AGB retrieval at the CGBRS after referring to related studies [49-51]. The 23 predictor variables included five variables of ALOS-2 PALSAR-2 data $(\mathrm{HV}, \mathrm{HH}, \mathrm{HV} / \mathrm{HH}, \mathrm{HH} / \mathrm{HV}$, and $\mathrm{HH}-\mathrm{HV}), 11$ multispectral bands of S-2, and seven vegetation indices. Using the predictor variables, we computed the explanatory variables in the prediction model of mangrove AGB retrieval (Table 3). Figure 4 illustrates the image composites of different sensors and vegetation indices, along with the SAR transformation, in the study area.

Table 3. List of vegetation indices used in the current study.

\begin{tabular}{|c|c|c|c|}
\hline Vegetation Index & Acronyms & Formula & References \\
\hline Ratio Vegetation Index & RVI & $\frac{B \text { Band } 8}{\text { Band } 4}$ & [28] \\
\hline Normalized Difference Vegetation Index & NDVI & $\frac{\text { Band8-Band4 }}{\text { Band } 8+\text { Band4 }}$ & [29] \\
\hline Soil Adjusted Vegetation Index & SAVI & $\begin{array}{l}(1+L)\left(\frac{\text { Band } 8-\text { Band } 4}{\text { Band8 }+2.4 B a n d 4+L}\right) \\
\text { in most conditions }\end{array}$ & [31] \\
\hline $\begin{array}{l}\text { Normalized Difference Index using } \\
\text { bands } 4 \text { and } 5 \text { of Sentinel-2 }\end{array}$ & NDI45 & $\frac{\text { Band5-Band } 4}{\text { Band5 }+ \text { Band } 4}$ & [32] \\
\hline Difference Vegetation Index & DVI & Band 8-Band 4 & [33] \\
\hline Green Difference Vegetation Index & GNDVI & $\frac{\text { Band } 8-\text { Band } 3}{\text { Band } 8+\text { Band } 3}$ & [34] \\
\hline Inverted Red-Edge Chlorophyll Index & IRECl & $\frac{\text { Band7-Band4 }}{\text { Band5/Band6 }}$ & [35] \\
\hline
\end{tabular}




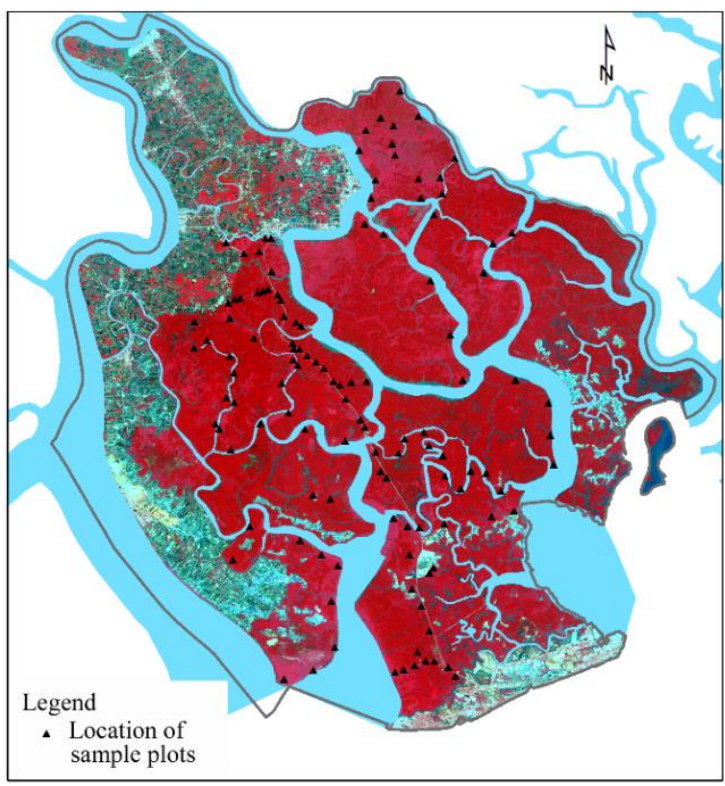

(a)

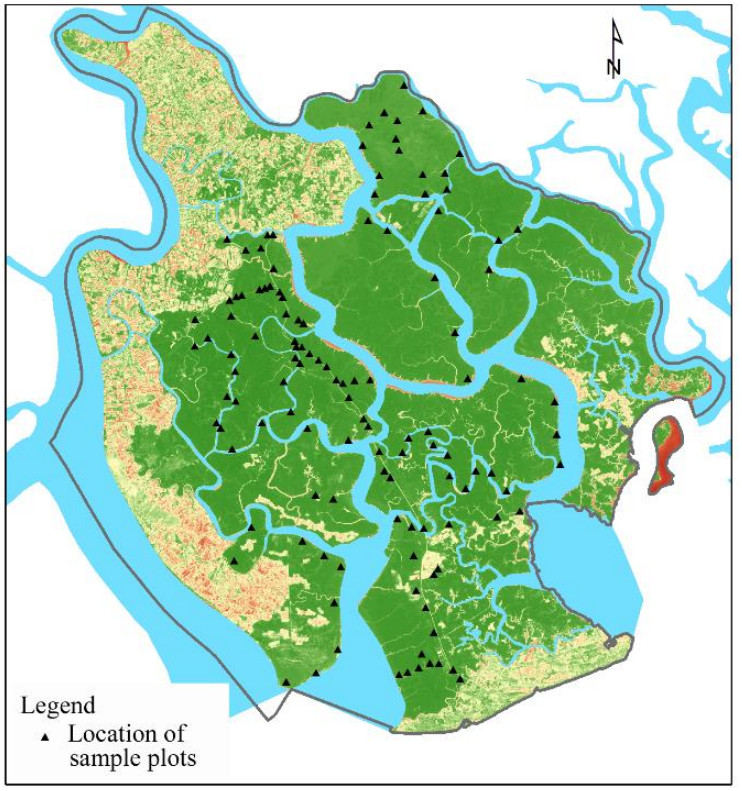

(c)

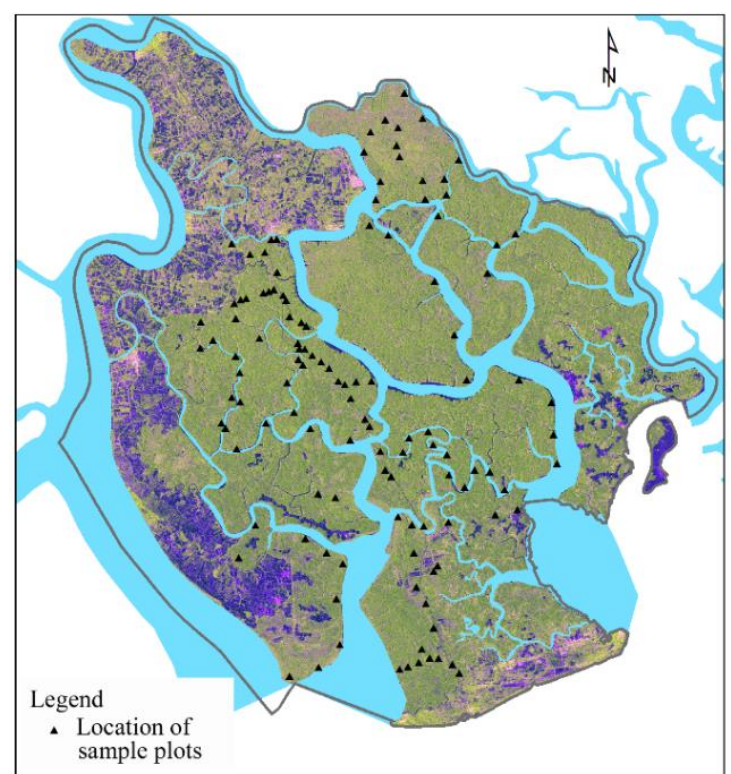

(b)

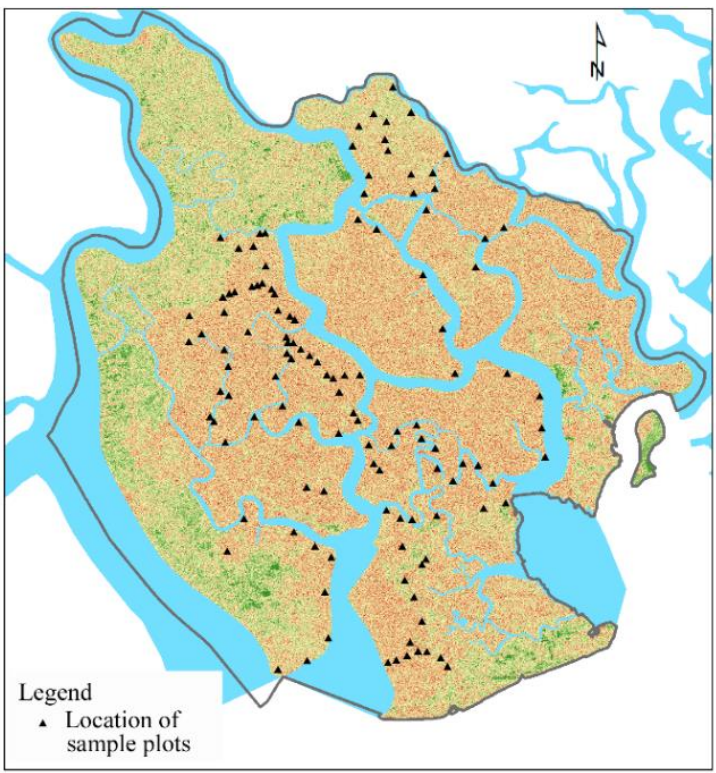

(d)

Figure 4. Illustrations of input variables in the study area. (a) Pseudo color composite of Sentinel-2 (RGB: Bands 8-4-3), (b) Pseudo color composite of ALOS-2 PALSAR-2 (RGB: HH-HV-HH/HV), (c) NDVI, (d) SAR transformation (HH-HV).

\subsection{Selection of Machine Learning Model}

To identify the best model for AGB retrieval in CGBSR, we compared the performances of several ML techniques (XGBR, GBR, GPR, RFR, and SVR). The SVR model best predicted the mangrove AGB in a coastal area of North Vietnam [9], whereas the RFR model delivered the best monitoring results of mangrove biomass changes in South Vietnam [10]. Therefore, SVR and RFR were selected for the present study. The other ML algorithms were chosen because they are commonly used for solving regression problems in various fields [40-42]. 


\subsubsection{Gradient Boosting Decision Trees Algorithms}

\section{a. Gradient Boosting Regression (GBR)}

GBR is an ensemble-based decision tree method that boosts the performance of weak learners to those of stronger ones. Each regression tree of the GBR learns the residual of each tree conclusion. The main purpose is to reduce the previous residuals and thereby decrease the model residual along the gradient direction. The results of all regression trees are integrated to give the final result $[52,53]$. The GBR model can handle mixed data types and is robust to outliers [54]. As GBR has not been widely applied to mangrove biomass estimation, it was considered for testing in the present study.

The parameters to be determined are the learning rate, number of trees, minimum number of samples required at a leaf node, maximum depth, and the number of features for the best split. The hyperparameters of the GBR model were optimized by five-fold cross-validation (CV) techniques.

\section{b. Extreme Gradient Boosting Regression (XGBR)}

The Extreme Gradient Boosting (XGB) algorithm, proposed by Chen and Guestrin [55], is a novel GBR technique that develops strong learners by an additive training process. To resolve the drawbacks of weakly supervised learning, the additive learning is divided into two phases: A learning phase fitted to the entire input data, followed by adjustment to the residuals. The fitting process is repeated many times until the stopping criteria are achieved. This algorithm is based on "boosting decision trees", which handle both classification and regression tasks in weakly supervised machine learning by the additive training strategies. The XGBR technique alleviates the undesired over-fitting problem.

The XGBR algorithm optimizes the loss function not by the first-order derivative (as in GBR) but by an efficient second-order expression. To avoid the over-fitting problem, the objective function treats the model complexity as a regularization term, and the regular term is added to the cost functions [55]. The XGBR model is quite generalizable and avoids both over-fitting and under-fitting. It also supports parallel computing to reduce computational time.

The parameters of XGBR are those of the GBR algorithm, and an additional parameter gamma $(\gamma)$ representing the minimum loss of further partitioning a leaf node of the tree. The larger the $\gamma$, the more conservative is the algorithm. The XGBR model was also optimized by five-fold CV in the Python environment.

\subsubsection{Support Vector Regression (SVR)}

SVM is a supervised learning technique based on the statistical learning theory developed by Vapnik [56]. This method is widely used for classification and regression tasks in computer vision, pattern recognition, and environmental problems. SVR is an SVM method that solves specific regression problems. A nonlinear kernel function in SVR transforms the dataset into a higher dimensional feature space, where the data can be treated by simple linear regression. In this study, the selected kernel function was the radial basis function (RBF), the most widely adopted kernel for optimizing forest AGBs in prior studies $[29,50]$.

The SVR model is generally configured by three hyperparameters: Epsilon $(\varepsilon)$, the regulation parameter $(C)$, and the kernel width $(\gamma)$ of the RBF. In the present study, these parameters were optimized through five-fold CV.

\subsubsection{Random Forests (RF)}

RF [57] is the most common bagging model applied to both classification and regression problems. For training, RFR creates multiple uncorrelated trees from a randomly selected subset of $2 / 3$ of the total samples (in-bag). The remaining $1 / 3$ of the total samples (out-of-bag, OOB) are used for estimating the OOB error and validating the method. A tree is grown from in-bag samples with $m$ features for optimizing the split at each node. In the absence of pruning, the tree reaches its largest possible extent. 
The RFR model produces (1) an OOB error and (2) the relative importance of each variable. From these outputs, it assesses the prediction accuracy and the contribution of each variable.

RFR is a high-performance non-parametric method that processes nonlinear data without overestimation during the training and testing phases. Accordingly, it has been widely employed in remote sensing $[58,59]$. The RFR requires the number of trees and the number of features $m$ for the split. In this study, both RFR parameters were optimized by five-fold CV in the Python environment.

\subsubsection{Gaussian Processes (GP)}

Based on the non-parametric Bayesian theory, GPs are applicable to both classification and nonlinear regression problems. The GPR model learns the fit function from a small dataset using various kernels, finding the probability distribution that best describes the data. The input data are assumed to follow a multivariate Gaussian distribution, and the noise is independent of the data measurements [60]. The mean vector and covariance matrix are estimated from the training data by mean and covariance functions, respectively, creating a detailed posterior distribution from which the confidence interval and uncertainty of the prediction results can be interpreted. The mean value of a GP represents the best estimation from the model, and the variance $\left(\sigma^{2}\right)$ helps to measure the confidence level. GPs are well-known as good predictors of biophysical parameters [61].

\subsection{Model Evaluation}

\subsubsection{Input Data for Model Running}

To create the input data for training models, the 121 sampling plots were divided into training set $(80 \%)$ and testing dataset $(20 \%)$ using the well-known Scikit-learn [46] library in Python programming environment. Because the measured plot size $\left(500 \mathrm{~m}^{2}\right)$ greatly exceeded the image pixel size $(10 \mathrm{~m})$, all satellite data were smoothed through a median filter with a window size of $5 \times 5$ pixels in the SciPy library [62].

\subsubsection{Hyperparameters Tuning in XGBR, GBR, RFR, SVR, and GPR}

Hyperparameter tuning is often required when optimizing machine learning techniques. In this work, the parameters of each ML model were optimized by grid searching and five-fold CV. The results are listed in Table 4.

Table 4. Optimized hyperparameters of the ML applied in this study.

\begin{tabular}{|c|c|c|c|c|c|}
\hline Algorithm & Learning_Rate/Epsilon & $\begin{array}{l}\text { Min_Samples_Leaf } \\
\text { Min_Child_Weight }\end{array}$ & Gamma & $\begin{array}{c}\text { Max_Depth/Max } \\
\text { Features }\end{array}$ & $\begin{array}{c}\text { n_Estimators or C } \\
\text { Value }\end{array}$ \\
\hline RFR & NA & 2 & NA & 5,15 & 50 \\
\hline SVR & 0.01 & NA & 1000 & NA & 1000 \\
\hline GBR & 0.2 & 5 & NA & 7,3 & 100 \\
\hline XGBR & 0.2 & 3 & 1 & 3 & 100 \\
\hline
\end{tabular}

In the GPR, we combined the RBF with a length scale of 100 and WhiteKernel with a noise level of 1.0. The hyperparameters and kernels were maintained during the training and testing phases.

\subsubsection{Feature Importance}

The variables in RFR and gradient boosting machine algorithms, such as XGBR and GBR are often ranked by the variable-importance approach $[55,63,64]$. Relative variable importance is computed as follows. The first step searches for a candidate subset of variables (in this case, by the grid search approach). Initially, the grid search includes all variables derived from the S-2, VIs, and ALOS-2 PALSAR-2 datasets. The datasets are input to the XGBR model, which ranks the variables in descending order of their importance based on the root mean squared error (RMSE) and the coefficient 
of determination $\left(R^{2}\right)$. Next, a certain number of the least important variables are removed, and the surviving variables form a variable subset. In this paper, the search/selection iterations were terminated when the $R^{2}$ of the prediction model of the subset did not improve the performance in the test set. The final step validates the selected variable subset and determines the relative variable importance (in this case, by the five-fold CV approach).

The modeling and generated variable importance of the XGBR model were implemented in the Python environment.

\subsubsection{Model Evaluation}

The model performances of the various ML techniques were evaluated and compared by the RMSE (Equation (2)) and $R^{2}$ (Equation (3)), which are widely employed in estimates of forest AGB biomass. Both standards evaluate the errors in a regression model from the differences between the measured data (the mangrove forest measurements) and the estimated AGB data [50]. A well-performing model will achieve a high $R^{2}$ and a low $[24,47]$.

$$
\begin{gathered}
\mathrm{RMSE}=\sqrt{\sum_{1}^{n} \frac{\left(y e_{i}-y m_{i}\right) 2}{n}} \\
R^{2}=\frac{\sum_{i=1}^{n}\left(y e_{i}-\overline{y e}\right)\left(y m_{i}-\overline{y m}\right)}{\sqrt{\sum_{i=1}^{n}\left(y e_{i}-\overline{y e}\right)^{2}\left(y m_{i}-\overline{y m}\right)^{2}}}
\end{gathered}
$$

In the above expressions, $y e_{i}$ is the mangrove AGB predicted by the ML model, $y m_{i}$ is the measured mangrove $\mathrm{AGB}, n$ is the total number of sampling plots, and $\overline{y e}$ and $\overline{y m}$ are the mean values of the predicted and measured mangrove AGBs, respectively.

\section{Results}

\subsection{Mangrove Tree Characteristics in CGBRS}

Table 5 gives the characteristics of the mangrove trees in the 121 sampling plots. The AGBs ranged from 7.26 to $305.41 \mathrm{Mg} \mathrm{ha}^{-1}$, with a mean of $97.54 \mathrm{Mg} \mathrm{ha}^{-1}$. The mangrove heights varied from 6.47 to $17.35 \mathrm{~m}$, and their DBHs ranged from 6.69 to $22.19 \mathrm{~cm}$. The mangrove tree densities ranged from 170 to 1680 trees $^{-1}$ (Table 5).

Table 5. Characteristics of the mangrove trees in CGBRS.

\begin{tabular}{ccccc}
\hline Attribute & Min & Max & Mean & $\begin{array}{c}\text { Standard } \\
\text { Deviation (SD) }\end{array}$ \\
\hline $\mathrm{DBH}(\mathrm{cm})$ & 6.69 & 22.19 & 13.24 & 3.5 \\
\hline $\mathrm{H}(\mathrm{m})$ & 6.47 & 17.35 & 11.87 & 2.5 \\
\hline Tree density $\left(\right.$ tree ha $\left.^{-1}\right)$ & 170 & 1680 & 694 & 26.45 \\
\hline AGB $\left(\mathrm{Mg} \mathrm{ha}^{-1}\right)$ & 7.26 & 305.41 & 97.54 & 5.88 \\
\hline
\end{tabular}

\subsection{Modeling Results, Assessment, and Comparison}

Table 6 and Figure 5 compare the performances of the five regression methods with all input variables derived from S-2 MSI, VIs, and ALOS-2 PALSAR-2 images for mangrove AGB estimation in the study area. The XGBR model incorporating the S-2 (11 MS bands), ALOS- 2 PALSAR-2 (5 bands), and VIs (7 bands) data achieved the highest performance (Table 6), with an $R^{2}$ of 0.805 and an RMSE of $28.13 \mathrm{Mg} \mathrm{ha}^{-1}$ in the testing dataset (23 predictor variables based on the fused S-2, the VIs and the ALOS-2 PALSAR-2 data), implying a good fit between the model estimates and field-based 
measurements. The next-highest performers were the GBR and RFR models. In contrast, the SVR and GPR models were unsuitable for retrieving the mangrove AGB at the study site (Table 6).

Table 6. Performance comparison of ML techniques on mangrove AGB estimation.

\begin{tabular}{|c|c|c|c|c|}
\hline No & Machine Learning Model & $R^{2}$ Training $(80 \%)$ & $R^{2}$ Testing (20\%) & RMSE (Mg ha-1) \\
\hline 1 & $\begin{array}{c}\text { Extreme Boosting regression } \\
\text { (XGBR) }\end{array}$ & 0.992 & 0.805 & 28.13 \\
\hline 2 & $\begin{array}{l}\text { Gradient Boosting regression } \\
\text { (GBR) }\end{array}$ & 0.998 & 0.632 & 39.54 \\
\hline 3 & $\begin{array}{l}\text { Random Forests regression } \\
\text { (RFR) }\end{array}$ & 0.721 & 0.468 & 48.44 \\
\hline 4 & $\begin{array}{c}\text { Support Vector regression } \\
\text { (SVR) }\end{array}$ & 0.480 & 0.421 & 48.49 \\
\hline 5 & $\begin{array}{c}\text { Gaussian Processes regression } \\
\text { (GPR) }\end{array}$ & 0.509 & 0.378 & 50.23 \\
\hline
\end{tabular}

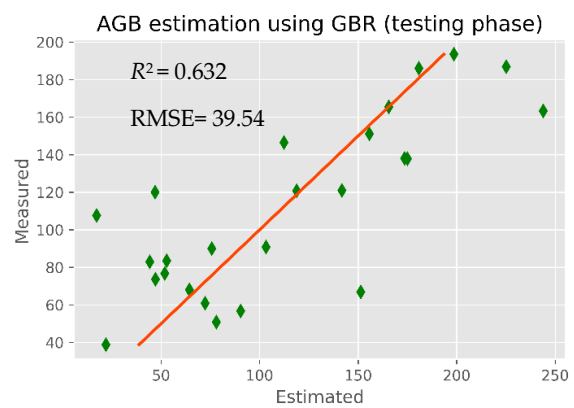

(a)

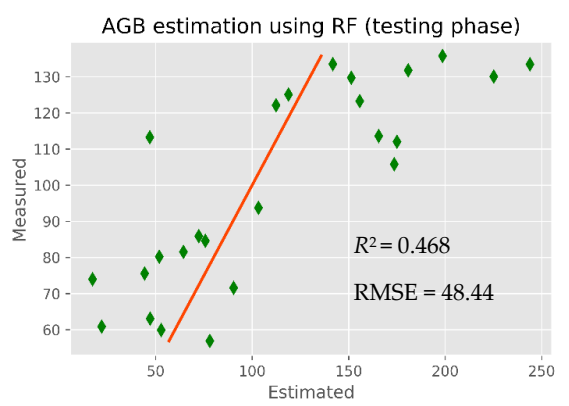

(c)

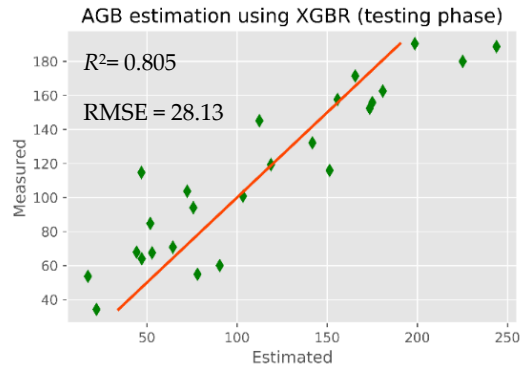

(b)

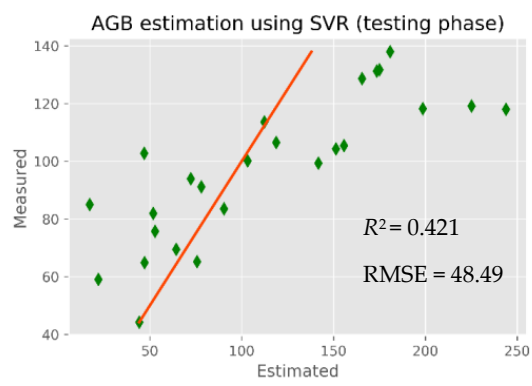

(d)

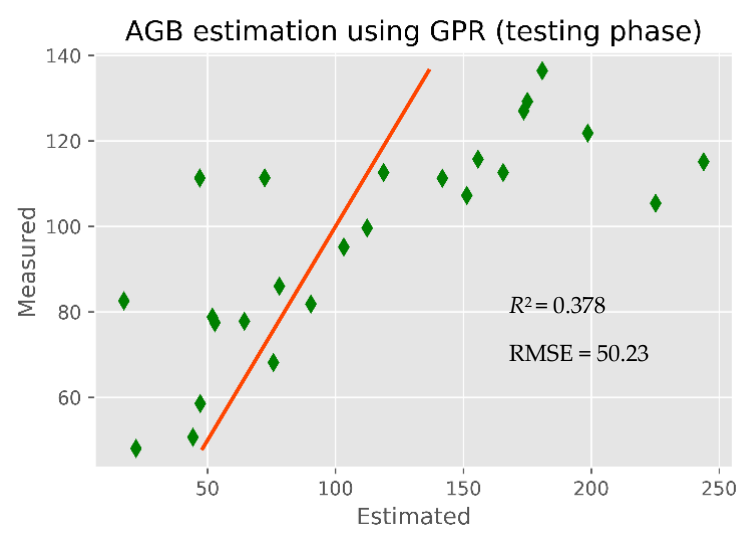

(e)

Figure 5. Scatter plots of the estimated ( $\mathrm{X}$ axis) versus the measured ( $\mathrm{Y}$ axis) mangrove AGB in the five ML models, integrating the data of S-2, ALOS-2 PALSAR-2, and VIs in the testing phase. (a) GBR, (b) XGBR, (c) RFR, (d) SVR, (e) GPR. 
Table 7 lists the performances of the XGBR method in five scenarios (SCs) of mangrove AGB prediction, using different combinations of the S-2, ALOS-2 PALSAR-2, and VIs data.

Table 7. Performance of the XGBR model using different numbers of variables. (Bold values highlight the best-performing model).

\begin{tabular}{cccc}
\hline Scenario (SC) & Number of Variables & $\boldsymbol{R}^{\mathbf{2}}$ Testing Set & RMSE $\mathbf{~} \mathbf{M g ~ h a}^{\mathbf{- 1}}$ ) \\
\hline SC1 & 11 variables from MS bands of S2 data & 0.600 & 36.54 \\
\hline SC2 & 5 variables from ALOS-2 PALSAR-2 data & 0.492 & 39.48 \\
\hline SC3 & 18 variables from MS bands and VIs from S2 & 0.739 & 34.86 \\
\hline SC4 & $\begin{array}{c}\text { 23 variables (11 MS bands + 7 vegetation indices + 5 } \\
\text { bands from ALOS-2 PALSAR-2) }\end{array}$ & 0.805 & 28.13 \\
\hline SC5 & 16 variables (11 MS bands + 5 bands from ALOS-2 & 0.656 & 43.25 \\
\hline
\end{tabular}

As clarified in Table 7, the XGBR model yielded a promising result in SC3 using the combined S-2 and VIs, but the model achieved a poor result in SC2 using the ALOS-2 PALSAR-2 alone. The performance in $\mathrm{SC} 1$ using the S-2 dataset alone was moderate. We concluded that fusing all data in SC4 boosted the prediction performance of XGBR for estimating the mangrove AGB in the study area. The visual results of the testing phase (Figure 5) reconfirm the high performance of mangrove AGB estimation by XGBR with the 23 variables of the fused data. Particularly, the green scatter points cluster around the blue line and the RMSE is small.

\subsection{Variable Importance}

Among the multispectral bands of S-2 MSI, the Red (665 nm), Vegetation Red Edge (704 nm), and the narrow NIR $(864 \mathrm{~nm})$ spectra were most sensitive to the mangrove AGB of the present study, followed by the SWIR spectrum (MS band 11 at $1610 \mathrm{~nm}$ ). Interestingly, among the seven VIs indices, the Inverted Red-Edge Chlorophyll Index (IRECl) and the Normalized Difference Index (NDI45) (bands 4 and 5 of S-2) were likely sensitive to the mangrove AGB in the study area. The band ratios derived from the incorporated $\mathrm{HH}$ and $\mathrm{HH}$ polarizations in the ALOS-2 PALSAR-2 data were also important for retrieving mangrove AGB in the biosphere reserve (see Figure 6). The backscatter coefficients of the crossed-polarimetric HV in ALOS-2 PALSAR-2 are likely more important than those of the HH for estimating the mangrove AGB in the study region (Figure 6).

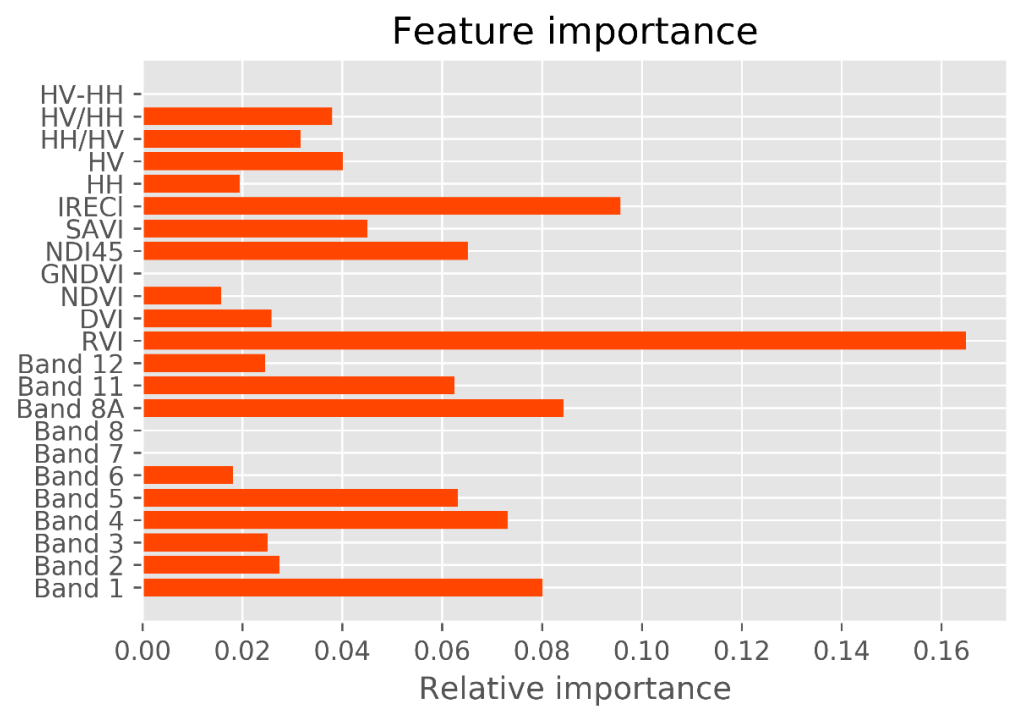

Figure 6. Variable importance comparison of S-2, VIs, and ALOS-2 PALSAR-2 data in this study. 


\subsection{Generation and Analysis of the AGB Map}

The prediction performance of the XGBR model in mangrove AGB retrieval was improved by integrating the Sentinel-2 multispectral bands, vegetation indices, and ALOS-2 PALSAR-2 datasets. Thus, the XGBR model was selected for retrieving mangrove AGB in a biosphere reserve. The final results were computed to a raster in GeoTiff format for visualizing in QGIS. The AGB map was interpreted by seven classes (Figure 7), obtaining mangrove AGBs from 11 to $293 \mathrm{Mg} \mathrm{ha}^{-1}$ (average = 106.93 $\mathrm{Mg} \mathrm{ha}^{-1}$ ). As can be seen from Figure 7, the biomass is highest in the core zone of the biosphere reserve and lower in the transition and buffer zones. These results are consistent with prior mangrove AGB estimates [17] and [65], in which the high biomass was mainly distributed in the core zone of the biosphere reserve, and the lower biomass was observed in the remaining zones.

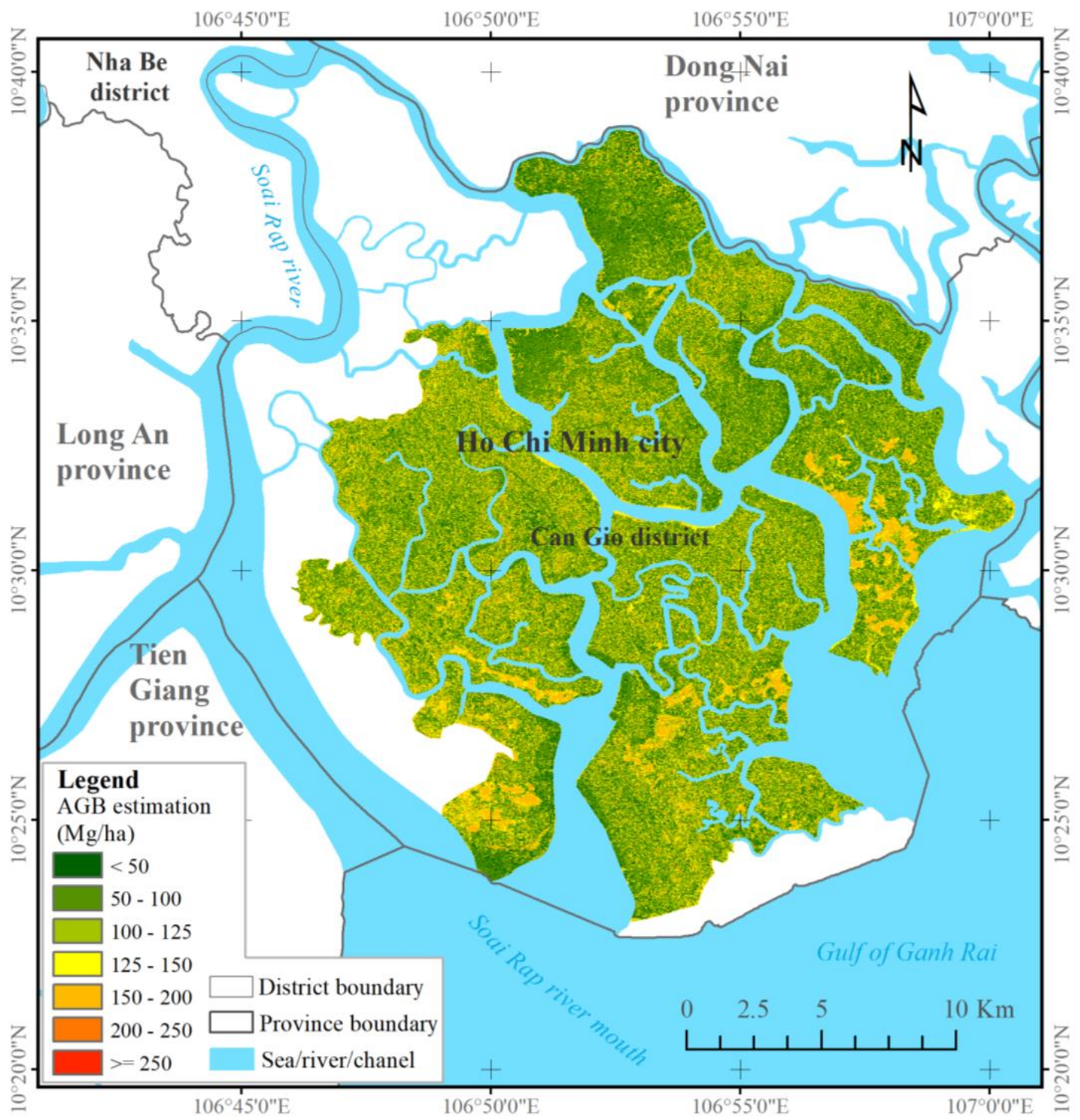

Figure 7. Estimated spatial distribution of mangrove AGB in the study area.

\section{Discussion}

The modeling results of mangrove AGB retrieval in the CGBSR obtained by the five ML models (XGBR, GBR, GPR, SVR, and RFR) are given in Table 6. Clearly, the XGBR model yielded the highest performance, with an $R^{2}$ and RMSE of 0.805 and $28.13 \mathrm{Mg} \mathrm{ha}^{-1}$, respectively. The worst performing model was GPR, with an $R^{2}$ and RMSE of 0.378 and $50.23 \mathrm{Mg} \mathrm{ha}^{-1}$, respectively. Both the XGBR model 
$\left(R^{2}=0.805\right)$ and GBR model $\left(R^{2}=0.632\right)$ were good predictors of mangrove AGB, indicating that the GBDT regression models were applicable to the study area, where the mangrove biomass is higher than in other mangrove regions of Vietnam. As shown in Table 7, the combined S-2 and ALOS-2 PALSAR data significantly improved the performance of estimating the mangrove AGB in the study area. These results are consistent with a recent previous study [50]. Overall, the XGBR model outperformed the existing algorithms in retrieving the mangrove AGB in a Vietnamese biosphere reserve.

Previous studies reported that long-wavelength PolSAR data, such as the $\mathrm{L}$ and the $\mathrm{P}$ bands, are well correlated with mangrove forest structures. Among these data, crossed-polarized HV appears to be most correlated with biophysical attributes $[13,66,67]$. The variable-importance analysis revealed that crossed-polarization $\mathrm{HV}$ is more sensitive to mangrove AGB in the study area than $\mathrm{HH}$ polarization (Figure 6), consistent with previous results [26,29]. However, mangrove forests in a biosphere reserve exhibit unique stand structures and species compositions that may saturate multispectral and SAR sensors. Data saturation of multispectral sensors such as Landsat TM, ETM+ or OLI, and the S-2 sensor degrades the prediction accuracy of mangrove AGBs in dense forest canopies. The saturation range of multispectral data reaches $100-150 \mathrm{Mg} \mathrm{ha}^{-1}$ in complex tropical forests, much higher than in mixed and pine forest ecosystems (with a saturation range of $>150$ to $<160 \mathrm{Mg} \mathrm{ha}^{-1}$ ) $[68,69]$. In several recent investigations, the saturation levels of the mangrove AGBs retrieved from SAR data ranged from above $100 \mathrm{Mg} \mathrm{ha}^{-1}$ [20] to below $150 \mathrm{Mg} \mathrm{ha}^{-1}$ [21,26]. This large range probably manifests from the root systems of different mangrove species in intertidal tropical and sub-tropical regions [13]. The sigma backscatter coefficients of the dual polarimetric data of ALOS-2 PALSAR-2 increased when the mangrove AGB fell below $100 \mathrm{Mg} \mathrm{ha}^{-1}$ and then saturated at a higher AGB because the high mangrove cover density extinguished the radar signals [70,71].

Biosphere reserves often consist of various mangrove species. The species types (i.e., R. appiculata, B. gymnorrhiza, and S. caseolaris) are densely grown and characterized by high DBH and tall height. Some species, such as A. germinans and C. decandra, form small but high-density mangrove patches in which high and low biomasses are easily underestimated and overestimated, respectively, by machine learning algorithms. In the current study, the XGBR model possibly over-estimated the low mangrove AGBs (below $50 \mathrm{Mg} \mathrm{ha}^{-1}$ ) and under-estimated the high values (over $250 \mathrm{Mg} \mathrm{ha}^{-1}$ ). Despite these limitations, the combined ALOS-2 PALSAR-2 and S-2 data sensitively detected mangrove AGBs exceeding $200 \mathrm{Mg} \mathrm{ha}^{-1}$ in the CGBRS (See Figure 5). Our findings agree with the conclusions of prior research on biosphere reserves $[17,65]$. Given the species complexity in mangrove biosphere reserves, we recommend the inclusion of species classification or richness indices for improved mangrove AGB estimation in future work $[19,21]$.

In the variable-importance results, the mangrove AGB in the study area was largely retrieved from the Red band and the Vegetation Red Edge band. A similar result was reported elsewhere [18,72]. The vegetation red edge, narrow NIR, and SWIR reflectance are likely to be more strongly correlated with forest biomass and carbon stock volume than visible reflectance [17]. Accordingly, the new vegetation index ND145, which is computed from the Sentinel-2 data bands, is a probable sensitive indicator of mangrove AGB. Band 8A in the narrow NIR and band 11 in the SWIR (1613 nm) also played a crucial role in the AGB retrieval. Interestingly, the IRECl derived from S-2 was strongly correlated with mangrove AGB in the biosphere reserve. More in-depth studies would elucidate the effectiveness of image transformations involving new vegetation indices derived from the Narrow NIR bands, SWIR of S-2 data, and other image transformations computed from the fully polarized data $\mathrm{HH}, \mathrm{HV}, \mathrm{VH}$, and VV) of the Gaofeng-3 and the ALOS-2 PALSAR-2 sensors in biosphere reserves.

To accurately estimate mangrove AGBs, researchers attempted multi-linear regression, which performed poorly with $R^{2}$ ranging from $0.43-0.65$ [13,21,73], and various ML algorithms such as GPR, MLPNN, SVR, and RFR $[17,18,29]$. ML approaches have proven more successful in mangrove AGB than multi-linear regression and other parametric methods [18,47], but the $R^{2}$ has rarely exceeded 0.70. Therefore, novel approaches for mangrove AGB estimation are urgently needed. In this research, the performance of the XGBR model was boosted by incorporating data from the ALOS-2 PALSAR-2, 
S-2 sensors. The result ( $R^{2}=0.805$ for the AGB of a mangrove biosphere reserve in the tropics) demonstrates the promise of this approach. Despite the good fit between the XGBR-predicted and measured-mean mangrove AGBs, the range of the predicted mangrove AGBs did not reach the extrema of the actual distribution range, which was maximized at $305.41 \mathrm{Mg} \mathrm{ha}^{-1}$ and minimized at $26 \mathrm{Mg} \mathrm{ha}^{-1}$ (Table 5). The predicted results may have been degraded by the saturation levels of the S2 MSI sensor and the dual polarimetric L-band ALOS-2 PALSAR-2 when retrieving mangrove AGB in intertidal areas. Although the AGB was well predicted by the XGBR model, the $R^{2}$ values in the training and testing phases were significantly different (Table 6). This difference is likely attributable to the mixed mangrove species planted in the CGBRS and the number of plots. To archive a more accurate forest AGB map, we should exploit the advantages of various novel GBDT algorithms with multi-sensor data integration [74]. In more intensive works, novel boosting decision tree techniques should exploit the full capability of multi-source EO data in different mangrove communities occupying tropical intertidal areas at different geographical locations, particularly those of biosphere reserves. Such developments are needed for rapid mangrove AGB monitoring in the future.

\section{Conclusions}

We report the first attempt to incorporate Sentinel-2 and ALOS-2 PALSAR-2 data into the extreme gradient boosting regression (XGBR) model and thereby estimate the mangrove AGB in Vietnam's Can Gio biosphere reserve. The XGBR model outperformed four other machine learning models in mangrove AGB retrieval in the study area. When provided with the Sentinel-2 and ALOS-2 PALSAR-2 data, XGBR estimated the mangrove AGB with satisfactory accuracy $\left(R^{2}=0.805\right.$, RMSE $=28.13 \mathrm{Mg}$ $\mathrm{ha}^{-1}$ ). Interestingly, we found that new vegetation indices derived from the Sentinel-2 data, such as the Normalized Difference Index (NDI45) and the Inverted Red-Edge Chlorophyll Index (IRECl), sensitively detected mangrove AGB in the biosphere reserve. In future investigations, the proposed approach should be tested in other tropical forest ecosystems.

Author Contributions: Conceptualization, T.D.P., L.V.N., N.N.L.; methodology, T.D.P.; validation, T.D.P., N.N.L., N.T.H.; data analysis, N.N.L., T.D.P., N.T.H.; field investigation, L.V.N., L.Q.K., T.T.T., H.X.T.; writing一original draft preparation, T.D.P., N.N.L., N.T.H.; writing—review and editing, T.D.P., N.N.L., J.X., N.T.H., N.Y.; visualization, T.D.P., L.V.N.; supervision, N.Y., W.T., All authors have read and approved the final version of this paper. All authors have read and agreed to the published version of the manuscript.

Funding: This research received no external funding.

Acknowledgments: The authors would like to thank the Japan Aerospace Exploration Agency (JAXA) for providing the ALOS-2 PALSAR-2 data for this research under the 2nd Earth Observation Research Announcement Collaborative Research Agreement between the JAXA and RIKEN AIP. The authors are grateful to mission No. VAST 01.07/20-21 from the Vietnam Academy of Science and Technology (VAST) for data support of this research.

Conflicts of Interest: The authors declare no conflict of interest.

\section{Abbreviations}

\begin{tabular}{lll}
\multicolumn{3}{l}{ List of abbreviations in this study } \\
No & Abbreviation & Full Name \\
1 & AGB & Above-Ground Biomass \\
2 & ALOS & The Advanced Land Observing Satellite \\
3 & ANN & Artificial Neuron Networks \\
4 & PALSAR & Phased Array type L-band Synthetic Aperture Radar \\
5 & TOA & Top Of Atmosphere \\
6 & BOA & Bottom Of Atmospheric
\end{tabular}




$\begin{array}{lll}7 & \text { CGBRS } & \text { Can Gio Biosphere Reserve in South Vietnam } \\ 8 & \text { CV } & \text { Cross-validation } \\ 9 & \text { DBH } & \text { Diameter at breast height } \\ 10 & \text { EO } & \text { Earth Observation } \\ 11 & \text { ESA } & \text { European Space Agency } \\ 12 & \text { GBDT } & \text { Gradient Boosting Decision Trees } \\ 13 & \text { GBR } & \text { Gradient Boosting Regression } \\ 14 & \text { GeoTiff } & \text { Tagged Image File Format for GIS applications } \\ 15 & \text { GP } & \text { Gaussian Processes } \\ 16 & \text { GPR } & \text { Gaussian Process Regression } \\ 17 & \text { GPS } & \text { Global Positioning System } \\ 18 & \text { JAXA } & \text { Japan Aerospace Exploration Agency } \\ 19 & \text { LiDAR } & \text { Light Detection and Ranging } \\ 20 & \text { ML } & \text { Machine Learning } \\ 21 & \text { MRV } & \text { Monitoring, Reporting, and Verification } \\ 22 & \text { MSI } & \text { Multispectral Instrument } \\ 23 & \text { NA } & \text { Not Available } \\ 24 & \text { QGIS } & \text { Quantum Geographic Information System } \\ 25 & \text { RBF } & \text { Radial Basis Function } \\ 26 & \text { REDD+ } & \text { Reducing Emissions from Deforestation and Forest Degradation } \\ 27 & \text { RFR } & \text { Random Forest Regression } \\ 28 & \text { RMSE } & \text { Root Mean Square Error } \\ 29 & \text { S2 } & \text { Sentinel-2 } \\ 30 & \text { SAR } & \text { Synthetic Aperture Radar } \\ 31 & \text { SC } & \text { Scenarios } \\ 32 & \text { SNAP } & \text { Sentinel Application Platform } \\ 33 & \text { SVM } & \text { Support Vector Machine } \\ 34 & \text { SVR } & \text { Support Vector Regression } \\ 35 & \text { SWIR } & \text { Short-Wave InfraRed } \\ 36 & \text { VIs } & \text { Vegetation indices } \\ 37 & \text { XGB } & \text { Extreme Gradient Boosting } \\ 38 & \text { XGBR } & \text { Extreme Gradient Boosting Regression } \\ & & \end{array}$

\section{References}

1. Alongi, D.M. Carbon sequestration in mangrove forests. Carbon Manag. 2012, 3, 313-322. [CrossRef]

2. Brander, L.M.; Wagtendonk, A.J.; Hussain, S.S.; McVittie, A.; Verburg, P.H.; de Groot, R.S.; van der Ploeg, S. Ecosystem service values for mangroves in Southeast Asia: A meta-analysis and value transfer application. Ecosyst. Serv. 2012, 1, 62-69. [CrossRef]

3. Richards, D.R.; Friess, D.A. Rates and drivers of mangrove deforestation in Southeast Asia, 2000-2012. Proc. Natl. Acad. Sci. USA 2016, 113, 344-349. [CrossRef] [PubMed]

4. $\quad$ Friess, D.A.; Rogers, K.; Lovelock, C.E.; Krauss, K.W.; Hamilton, S.E.; Lee, S.Y.; Lucas, R.; Primavera, J.; Rajkaran, A.; Shi, S. The State of the World's Mangrove Forests: Past, Present, and Future. Annu. Rev. Environ. Resour. 2019, 44, 89-115. [CrossRef]

5. Pham, T.D.; Yoshino, K. Impacts of mangrove management systems on mangrove changes in the Northern Coast of Vietnam. Tropics 2016, 24, 141-151. [CrossRef]

6. Friess, D.A.; Webb, E.L. Variability in mangrove change estimates and implications for the assessment of ecosystem service provision. Glob. Ecol. Biogeogr. 2014, 23, 715-725. [CrossRef]

7. Lv, Z.Y.; Liu, T.F.; Zhang, P.; Benediktsson, J.A.; Lei, T.; Zhang, X. Novel Adaptive Histogram Trend Similarity Approach for Land Cover Change Detection by Using Bitemporal Very-High-Resolution Remote Sensing Images. IEEE Trans. Geosci. Remote Sens. 2019, 57, 9554-9574. [CrossRef]

8. Zhao, T.; Bergen, K.M.; Brown, D.G.; Shugart, H.H. Scale dependence in quantification of land-cover and biomass change over Siberian boreal forest landscapes. Landsc. Ecol. 2009, 24, 1299. [CrossRef] 
9. Lv, Z.; Liu, T.; Zhang, P.; Atli Benediktsson, J.; Chen, Y. Land Cover Change Detection Based on Adaptive Contextual Information Using Bi-Temporal Remote Sensing Images. Remote Sens. 2018, 10, 901. [CrossRef]

10. Clough, B.F.; Dixon, P.; Dalhaus, O. Allometric Relationships for Estimating Biomass in Multi-stemmed Mangrove Trees. Aust. J. Bot. 1997, 45, 1023-1031. [CrossRef]

11. Komiyama, A.; Ong, J.E.; Poungparn, S. Allometry, biomass, and productivity of mangrove forests: A review. Aquat. Bot. 2008, 89, 128-137. [CrossRef]

12. Hirata, Y.; Tabuchi, R.; Patanaponpaiboon, P.; Poungparn, S.; Yoneda, R.; Fujioka, Y. Estimation of aboveground biomass in mangrove forests using high-resolution satellite data. J. For. Res. 2014, 19, 34-41. [CrossRef]

13. Hamdan, O.; Khali Aziz, H.; Mohd Hasmadi, I. L-band ALOS PALSAR for biomass estimation of Matang Mangroves, Malaysia. Remote Sens. Environ. 2014, 155, 69-78. [CrossRef]

14. Darmawan, S.; Takeuchi, W.; Vetrita, Y.; Wikantika, K.; Sari, D.K. Impact of Topography and Tidal Height on ALOS PALSAR Polarimetric Measurements to Estimate Aboveground Biomass of Mangrove Forest in Indonesia. J. Sens. 2015, 2015, 13. [CrossRef]

15. Kauffman, J.B.; Donato, D.C. Protocols for the Measurement, Monitoring and Reporting of Structure, Biomass, and Carbon Stocks in Mangrove Forests; CIFOR: Bogor, Indonesia, 2012.

16. Ahmed, N.; Glaser, M. Coastal aquaculture, mangrove deforestation and blue carbon emissions: Is REDD+ a solution? Mar. Policy 2016, 66, 58-66. [CrossRef]

17. Pham, L.T.H.; Brabyn, L. Monitoring mangrove biomass change in Vietnam using SPOT images and an object-based approach combined with machine learning algorithms. ISPRS J. Photogramm. Remote Sens. 2017, 128, 86-97. [CrossRef]

18. Jachowski, N.R.A.; Quak, M.S.Y.; Friess, D.A.; Duangnamon, D.; Webb, E.L.; Ziegler, A.D. Mangrove biomass estimation in Southwest Thailand using machine learning. Appl. Geogr. 2013, 45, 311-321. [CrossRef]

19. Zhu, Y.; Liu, K.; Liu, L.; Wang, S.; Liu, H. Retrieval of Mangrove Aboveground Biomass at the Individual Species Level with WorldView-2 Images. Remote Sens. 2015, 7, 12192-12214. [CrossRef]

20. Lucas, R.M.; Mitchell, A.L.; Rosenqvist, A.; Proisy, C.; Melius, A.; Ticehurst, C. The potential of L-band SAR for quantifying mangrove characteristics and change: Case studies from the tropics. Aquat. Conserv. Mar. Freshw. Ecosyst. 2007, 17, 245-264. [CrossRef]

21. Pham, T.D.; Yoshino, K. Aboveground biomass estimation of mangrove species using ALOS-2 PALSAR imagery in Hai Phong City, Vietnam. APPRES 2017, 11, 026010. [CrossRef]

22. Maeda, Y.; Fukushima, A.; Imai, Y.; Tanahashi, Y.; Nakama, E.; Ohta, S.; Kawazoe, K.; Akune, N. Estimating carbon stock changes of mangrove forests using satellite imagery and airborne lidar data in the south Sumatra state, Indonesia. ISPRS Int. Arch. Photogramm. Remote Sens. Spat. Inf. Sci. 2016, 705-709. [CrossRef]

23. Fatoyinbo, T.; Feliciano, E.A.; Lagomasino, D.; Lee, S.K.; Trettin, C. Estimating mangrove aboveground biomass from airborne LiDAR data: A case study from the Zambezi River delta. Environ. Res. Lett. 2018, 13, 025012. [CrossRef]

24. Wang, D.; Wan, B.; Liu, J.; Su, Y.; Guo, Q.; Qiu, P.; Wu, X. Estimating aboveground biomass of the mangrove forests on northeast Hainan Island in China using an upscaling method from field plots, UAV-LiDAR data and Sentinel-2 imagery. Int. J. Appl. Earth Obs. Geoinf. 2020, 85, 101986. [CrossRef]

25. Wang, D.; Wan, B.; Qiu, P.; Zuo, Z.; Wang, R.; Wu, X. Mapping Height and Aboveground Biomass of Mangrove Forests on Hainan Island Using UAV-LiDAR Sampling. Remote Sens. 2019, 11, 2156. [CrossRef]

26. Pham, T.D.; Yoshino, K.; Bui, D.T. Biomass estimation of Sonneratia caseolaris (L.) Engler at a coastal area of Hai Phong city (Vietnam) using ALOS-2 PALSAR imagery and GIS-based multi-layer perceptron neural networks. Gisci. Remote Sens. 2017, 54, 329-353. [CrossRef]

27. Wu, C.; Shen, H.; Shen, A.; Deng, J.; Gan, M.; Zhu, J.; Xu, H.; Wang, K. Comparison of machine-learning methods for above-ground biomass estimation based on Landsat imagery. APPRES 2016, 10, 035010. [CrossRef]

28. López-Serrano, P.M.; López-Sánchez, C.A.; Álvarez-González, J.G.; García-Gutiérrez, J. A Comparison of Machine Learning Techniques Applied to Landsat-5 TM Spectral Data for Biomass Estimation. Can. J. Remote Sens. 2016, 42, 690-705. [CrossRef]

29. Pham, T.D.; Yoshino, K.; Le, N.; Bui, D. Estimating Aboveground Biomass of a Mangrove Plantation on the Northern coast of Vietnam using machine learning techniques with an integration of ALOS-2 PALSAR-2 and Sentinel-2A data. Int. J. Remote Sens. 2018, 39, 7761-7788. [CrossRef] 
30. Huang, G.; Wu, L.; Ma, X.; Zhang, W.; Fan, J.; Yu, X.; Zeng, W.; Zhou, H. Evaluation of CatBoost method for prediction of reference evapotranspiration in humid regions. J. Hydrol. 2019, 574, 1029-1041. [CrossRef]

31. Gumus, M.; Kiran, M.S. Crude oil price forecasting using XGBoost. In Proceedings of the 2017 International Conference on Computer Science and Engineering (UBMK), Antalya, Turkey, 5-7 October 2017; pp. 1100-1103.

32. Sun, Y.; Gao, C.; Li, J.; Wang, R.; Liu, J. Evaluating urban heat island intensity and its associated determinants of towns and cities continuum in the Yangtze River Delta Urban Agglomerations. Sustain. Cities Soc. 2019, 50, 101659. [CrossRef]

33. Ghatkar, J.G.; Singh, R.K.; Shanmugam, P. Classification of algal bloom species from remote sensing data using an extreme gradient boosted decision tree model. Int. J. Remote Sens. 2019, 40, 9412-9438. [CrossRef]

34. Li, P.; Zhang, J.-S. A New Hybrid Method for China's Energy Supply Security Forecasting Based on ARIMA and XGBoost. Energies 2018, 11, 1687. [CrossRef]

35. Veettil, B.K.; Ward, R.D.; Quang, N.X.; Trang, N.T.T.; Giang, T.H. Mangroves of Vietnam: Historical development, current state of research and future threats. Estuar. Coast. Shelf Sci. 2019, 218, 212-236. [CrossRef]

36. Tuan, L.D.; Oanh, T.T.K.; Thanh, C.V.; Quy, N.D. Can Gio Mangrove Biosphere Reserve; Agricultural Publishing House: Ho Chi Minh City, Vietnam, 2002; p. 311.

37. Hong, P.N.; San, H.T. Mangroves of Vietnam; IUCN: Bangkok, Thailand, 1993; p. 173.

38. Vogt, J.; Kautz, M.; Fontalvo Herazo, M.L.; Triet, T.; Walther, D.; Saint-Paul, U.; Diele, K.; Berger, U. Do canopy disturbances drive forest plantations into more natural conditions?-A case study from Can Gio Biosphere Reserve, Viet Nam. Glob. Planet. Chang. 2013, 110, 249-258. [CrossRef]

39. Ong, J.E.; Gong, W.K.; Wong, C.H. Allometry and partitioning of the mangrove, Rhizophora apiculata. For. Ecol. Manag. 2004, 188, 395-408. [CrossRef]

40. Komiyama, A.; Poungparn, S.; Kato, S. Common allometric equations for estimating the tree weight of mangroves. J. Trop. Ecol. 2005, 21, 471-477. [CrossRef]

41. Clough, B.F.; Scott, K. Allometric relationships for estimating above-ground biomass in six mangrove species. For. Ecol. Manag. 1989, 27, 117-127. [CrossRef]

42. Kangkuso, A.; Jamili, J.; Septiana, A.; Raya, R.; Sahidin, I.; Rianse, U.; Rahim, S.; Alfirman, A.; Sharma, S.; Nadaoka, K. Allometric models and aboveground biomass of Lumnitzera racemosa Willd. forest in Rawa Aopa Watumohai National Park, Southeast Sulawesi, Indonesia. For. Sci. Technol. 2016, 12, 43-50. [CrossRef]

43. Binh, C.H.; Nam, V.N. Carbon sequestration of Ceriops zippeliana in Can Gio mangroves. In Studies in Can Gio Mangrove Biosphere Reserve, Ho Chi Minh City, Viet Nam; ISME: Okinawa, Japan, 2014; p. 51.

44. Shimada, M.; Isoguchi, O.; Tadono, T.; Isono, K. PALSAR Radiometric and Geometric Calibration. IEEE Trans. Geosci. Remote Sens. 2009, 47, 3915-3932. [CrossRef]

45. Drusch, M.; Del Bello, U.; Carlier, S.; Colin, O.; Fernandez, V.; Gascon, F.; Hoersch, B.; Isola, C.; Laberinti, P.; Martimort, P.; et al. Sentinel-2: ESA's Optical High-Resolution Mission for GMES Operational Services. Remote Sens. Environ. 2012, 120, 25-36. [CrossRef]

46. Pedregosa, F.; Varoquaux, G.; Gramfort, A.; Michel, V.; Thirion, B.; Grisel, O.; Blondel, M.; Prettenhofer, P.; Weiss, R.; Dubourg, V. Scikit-learn: Machine learning in Python. J. Mach. Learn. Res. 2011, 12, 2825-2830.

47. Navarro, J.A.; Algeet, N.; Fernández-Landa, A.; Esteban, J.; Rodríguez-Noriega, P.; Guillén-Climent, M.L. Integration of UAV, Sentinel-1, and Sentinel-2 Data for Mangrove Plantation Aboveground Biomass Monitoring in Senegal. Remote Sens. 2019, 11. [CrossRef]

48. Castillo, J.A.A.; Apan, A.A.; Maraseni, T.N.; Salmo, S.G. Estimation and mapping of above-ground biomass of mangrove forests and their replacement land uses in the Philippines using Sentinel imagery. ISPRS J. Photogramm. Remote Sens. 2017, 134, 70-85. [CrossRef]

49. Patil, V.; Singh, A.; Naik, N.; Unnikrishnan, S. Estimation of Mangrove Carbon Stocks by Applying Remote Sensing and GIS Techniques. Wetlands 2015, 35, 695-707. [CrossRef]

50. Vafaei, S.; Soosani, J.; Adeli, K.; Fadaei, H.; Naghavi, H.; Pham, T.D.; Tien Bui, D. Improving Accuracy Estimation of Forest Aboveground Biomass Based on Incorporation of ALOS-2 PALSAR-2 and Sentinel-2A Imagery and Machine Learning: A Case Study of the Hyrcanian Forest Area (Iran). Remote Sens. 2018, 10, 172. [CrossRef]

51. Ghosh, S.M.; Behera, M.D. Aboveground biomass estimation using multi-sensor data synergy and machine learning algorithms in a dense tropical forest. Appl. Geogr. 2018, 96, 29-40. [CrossRef] 
52. Friedman, J.H. Greedy function approximation: A gradient boosting machine. Ann. Stat. 2001, 29, 1189-1232. [CrossRef]

53. Friedman, J.H. Stochastic gradient boosting. Comput. Stat. Data Anal. 2002, 38, 367-378. [CrossRef]

54. Wei, Z.; Meng, Y.; Zhang, W.; Peng, J.; Meng, L. Downscaling SMAP soil moisture estimation with gradient boosting decision tree regression over the Tibetan Plateau. Remote Sens. Environ. 2019, 225, 30-44. [CrossRef]

55. Chen, T.; Guestrin, C. Xgboost: A scalable tree boosting system. In Proceedings of the 22nd Acm Sigkdd International Conference on Knowledge Discovery and Data Mining, San Francisco, CA, USA, 13-17 August 2016; ACM: New York, NY, USA; pp. 785-794.

56. Vapnik, V. The Nature of Statistical Learning Theory; Springer Science \& Business Media: Berlin/Heidelberg, Germany, 2013.

57. Breiman, L. Random Forests. Mach. Learn. 2001, 45, 5-32. [CrossRef]

58. Belgiu, M.; Drăguţ, L. Random forest in remote sensing: A review of applications and future directions. ISPRS J. Photogramm. Remote Sens. 2016, 114, 24-31. [CrossRef]

59. Pham, T.D.; Xia, J.; Baier, G.; Le, N.N.; Yokoya, N. Mangrove Species Mapping Using Sentinel-1 and Sentinel-2 Data in North Vietnam. In Proceedings of the IGARSS 2019-2019 IEEE International Geoscience and Remote Sensing Symposium, Yokohama, Japan, 28 July-2 August 2019; pp. 6102-6105.

60. Perez-Cruz, F.; Vaerenbergh, S.V.; Murillo-Fuentes, J.J.; Lazaro-Gredilla, M.; Santamaria, I. Gaussian Processes for Nonlinear Signal Processing: An Overview of Recent Advances. IEEE Signal. Process. Mag. 2013, 30, 40-50. [CrossRef]

61. Rasmussen, C.E.; Williams, C.K. Gaussian Processes for Machine Learning; MIT Press: Cambridge, MA, USA, 2006; Volume 1.

62. Jones, E.; Oliphant, T.; Peterson, P. SciPy: Open Source Scientific Tools for Python. 2001. Available online: https://www.scienceopen.com/document?vid=ab12905a-8a5b-43d8-a2bb-defc771410b9 (accessed on 4 August 2019).

63. Grömping, U. Variable Importance Assessment in Regression: Linear Regression versus Random Forest. Am. Stat. 2009, 63, 308-319. [CrossRef]

64. Li, Y.; Li, C.; Li, M.; Liu, Z. Influence of Variable Selection and Forest Type on Forest Aboveground Biomass Estimation Using Machine Learning Algorithms. Forests 2019, 10, 1073. [CrossRef]

65. Nguyen Viet, L.; To Trong, T.; Luong Anh, K.; Nguyen Thanh, H. Biomass estimation and mapping of can GIO mangrove biosphere reserve in south of viet nam using ALOS-2 PALSAR-2 data. Appl. Ecol. Environ. Res. 2019, 17, 15-31.

66. Lucas, R.; Armston, J.; Fairfax, R.; Fensham, R.; Accad, A.; Carreiras, J.; Kelley, J.; Bunting, P.; Clewley, D.; Bray, S.; et al. An Evaluation of the ALOS PALSAR L-Band Backscatter-Above Ground Biomass Relationship Queensland, Australia: Impacts of Surface Moisture Condition and Vegetation Structure. IEEE J. Sel. Top. Appl. Earth Obs. Remote Sens. 2010, 3, 576-593. [CrossRef]

67. Schlund, M.; Davidson, M. Aboveground Forest Biomass Estimation Combining L- and P-Band SAR Acquisitions. Remote Sens. 2018, 10, 1151. [CrossRef]

68. Foody, G.M.; Boyd, D.S.; Cutler, M.E.J. Predictive relations of tropical forest biomass from Landsat TM data and their transferability between regions. Remote Sens. Environ. 2003, 85, 463-474. [CrossRef]

69. Cutler, M.E.J.; Boyd, D.S.; Foody, G.M.; Vetrivel, A. Estimating tropical forest biomass with a combination of SAR image texture and Landsat TM data: An assessment of predictions between regions. ISPRS J. Photogramm. Remote Sens. 2012, 70, 66-77. [CrossRef]

70. Proisy, C.; Couteron, P.; Fromard, F. Predicting and mapping mangrove biomass from canopy grain analysis using Fourier-based textural ordination of IKONOS images. Remote Sens. Environ. 2007, 109, 379-392. [CrossRef]

71. Joshi, N.; Mitchard, E.T.A.; Brolly, M.; Schumacher, J.; Fernández-Landa, A.; Johannsen, V.K.; Marchamalo, M.; Fensholt, R. Understanding 'saturation' of radar signals over forests. Sci. Rep. 2017, 7, 3505. [CrossRef] [PubMed]

72. Chrysafis, I.; Mallinis, G.; Siachalou, S.; Patias, P. Assessing the relationships between growing stock volume and Sentinel-2 imagery in a Mediterranean forest ecosystem. Remote Sens. Lett. 2017, 8, 508-517. [CrossRef] 
73. Wicaksono, P.; Danoedoro, P.; Hartono; Nehren, U. Mangrove biomass carbon stock mapping of the Karimunjawa Islands using multispectral remote sensing. Int. J. Remote Sens. 2016, 37, 26-52. [CrossRef]

74. Pham, T.D.; Yokoya, N.; Bui, D.T.; Yoshino, K.; Friess, D.A. Remote Sensing Approaches for Monitoring Mangrove Species, Structure, and Biomass: Opportunities and Challenges. Remote Sens. 2019, 11, 230. [CrossRef] 